\title{
The relationship between frailty syndrome and quality of life in older patients following acute coronary syndrome
}

This article was published in the following Dove Press journal:

Clinical Interventions in Aging

\author{
Izabella Uchmanowicz' \\ Magdalena Lisiak' \\ Marta Wleklik' \\ Piotr Gurowiec ${ }^{2}$ \\ Marta Kałużna-Oleksy ${ }^{3}$ \\ 'Department of Clinical Nursing, Faculty \\ of Health Sciences, Wroclaw Medical \\ University, Wroclaw 5|-6|8, Poland; \\ ${ }^{2}$ Department of Nursing, Public Higher \\ Medical Professional School in Opole, \\ Opole 45-060, Poland; ${ }^{3}$ Ist Cardiology \\ Department, University Hospital of \\ Lord's Transfiguration Partner, Poznań \\ University of Medical Sciences, Poznan \\ 6I-848, Poland
}

Purpose: Elderly patients with ST-segment-elevation myocardial infarction (STEMI) have a high risk of mortality, which is particularly high in the first 30 days. Quality of life (QoL) and risk-benefit assessments are of pivotal importance in the elderly. The objective of this study is to assess the relationship between frailty syndrome (FS) and QoL in patients following acute coronary syndrome (ACS) non-ST elevation myocardial infarction (NSTEMI).

Patients and Methods: The study involved 100 patients (61 men, 39 women, the average age: $\mathrm{M} \pm \mathrm{SD}=66.12 \pm 10.92$ years). The study used standardized research tools: a questionnaire to assess QoL (World Health Organization Quality of Life Scale Brief version), and a questionnaire to assess FS (Tilburg Frailty Indicator).

Results: FS occurred in $80 \%$ of patients after ACS. FS has a negative impact on the QoL of patients with ACS. The most important domain of FS in the studied group was the psychological: $\mathrm{M} \pm \mathrm{SD}=2.2 \pm 0.75$ points. The greater $\mathrm{FS}$ in the physical domain, the lower the QoL in all areas. The greater FS in the social domain, the lower the QoL in psychological and social fields. Self-evaluation of patient QoL was $\mathrm{M} \pm \mathrm{SD}=3.68 \pm 0.71$ points. Selfassessment of health was $\mathrm{M} \pm \mathrm{SD}=2.59 \pm 0.98$ points.

Conclusion: Patients with a coexisting FS have a poorer QoL in the physical, psychological, social, and environmental fields. For a multidisciplinary team, these findings can help make the therapeutic decision for frail patients who have poor QoL. Frailty among elderly patients with ACS can be considered as a determinant of high risk of adverse outcomes.

Keywords: frailty syndrome, quality of life, acute coronary syndrome, Tilburg Frailty Indicator

\section{Introduction}

Coronary artery disease (CAD) is one of the leading causes of death in Europe, in both men and women. ${ }^{1}$ According to the European Society of Cardiology (ESC) guidelines, the definition of the acute coronary syndrome (ACS) includes unstable angina (UA), ST-segment-elevation myocardial infarction (STEMI), and non-ST elevation myocardial infarction (NSTEMI). ${ }^{2,3}$

The incidence of cardiovascular disease is especially high in older adults. As the

Correspondence: Izabella Uchmanowicz Department of Clinical Nursing, Faculty of Health Sciences, Wroclaw Medical University, Bartla 5, Wroclaw 5I-6I8, Poland

Tel +4 87I 784 I824

Fax +48713459324

Email izabella.uchmanowicz@umed.wroc.pl number of older people in the general population continues to increase, so does the number of these incidents. Patients aged 75 and older represent one-third of those hospitalized with acute ischemic events, and they account for more than half of all cardiac deaths. ${ }^{4}$ Age has been reported as one of the most important risk predictors in patients admitted with NSTEMI. ${ }^{5}$ 
It has also been shown that older people have a significantly higher burden of medical comorbidities than patients aged $<75$ years. ${ }^{6-8}$ They also have higher rates of cognitive and functional impairment. ${ }^{9}$ Moreover, older patients with myocardial infarction (MI) are a heterogeneous population who may present with atypical symptoms, ${ }^{10}$ thereby making diagnoses more difficult. The IFFANIAM study (impact of frailty and functional status on older patients with ST-segment elevation myocardial infarction undergoing primary angioplasty) is a multicenter registry to assess the prognostic value of frailty and other aging-related variables in patients with STEMI aged 75 years and older. ${ }^{11}$

The lack of guidelines and risk stratification when it comes to diagnosing older patients should lead to a more individualized approach. Quality of life (QoL) and riskbenefit assessments are of pivotal importance. ${ }^{12}$ Health care providers need an understanding of conditions unique to these patients, such as frailty syndrome (FS) and cognitive impairment, which influence treatment goals and outcomes. ${ }^{10}$ Treatment strategy selection is crucial, and many important factors must be taken into consideration, especially in the context of STEMI. It has been reported that older patients tend to experience a longer door-toballoon time (DTBT) than their younger cohorts. ${ }^{6,7}$ Older patients with STEMI have a high risk of mortality, which is especially evident in the first 30 days. ${ }^{13} \mathrm{~A}$ similar situation is observed with NSTEMI. Community practice has also revealed a lower use of cardiovascular medication, as well as invasive treatment, even among older patients with ACS who would stand to benefit. ${ }^{10}$

FS is viewed as a significant health problem for older adults in European countries. ${ }^{14,15}$ In accordance with the consensus of the American Geriatrics Society (AGS), FS is defined as a condition characterized by a decreased physiological function that results in both reduced functional reserves and reduced immunity to stress factors. This leads to adverse consequences. ${ }^{16} \mathrm{FS}$ is an important risk factor in the development of complications in older adults and those with chronic illnesses. The incidence frequency of FS increases with age; therefore, an increasing number of FS cases will be observed if the current trend of lengthening lifespans continues. ${ }^{17}$ The incidence of FS is varied and depends on the population studied and the research tools used. The Cardiovascular Health Study scale (CHS) study found that the incidence of FS is $3.9 \%$ in those aged $65-74$ and that this increases to $25 \%$ in those aged 85 or above. The study also found that FS is more common in women than men $(8 \%$ versus $5 \%$, respectively). ${ }^{17}$ Research has underscored that those with co-occurring FS belong to a high-risk group when it comes to developing adverse consequences that include hospitalization, institutionalization, disability, and death. ${ }^{17-21}$ Research has also highlighted that FS contributes to decreased independence, QoL, and general well-being.

The main objective of this study was to assess the relationship between co-occurring FS and QoL in patients following ACS. It was assumed that FS would have a negative impact on QoL and that QoL would be lower in the physical, psychological, social, and environmental domains.

\section{Material and methods Study design and settings}

This was an observational, prospective, and cross-sectional study. It was conducted from February 2017 to July 2017. The STROBE guidelines (Strengthening the Reporting of Observational Studies in Epidemiology) were followed.

\section{Study participants and selection}

The study sample included 100 older patients (61 men and 39 women aged $\geq 65$ years) who had been hospitalized due to ACS in cardiological wards at the Military Clinical Hospital No. 4 in Wroclaw, Poland. Participation in the study was voluntary and anonymous. At the stage of inclusion in the study, each patient was informed of the study process and of their option to withdraw at any point. The inclusion criteria were as follows: (1) NSTEMI was identified based on the ESC guidelines, (2) age was $\geq 65$ years, and (3) each patient had given written consent for taking part in the study.

Data collection was performed using a diagnostic questionnaire followed by medical documentation analysis. It considered several sociodemographic parameters: age, gender, marital status, education, professional status, and current place of residence. Clinical parameters included comorbidities, prescribed medications, duration of $\mathrm{CAD}$, number of hospitalizations due to ACS, and tobacco smoking.

\section{Ethical considerations}

The study protocol was approved by the independent Bioethics Committee of the Wroclaw Medical University (decision no. KB-83/2017). The study was carried out in accordance with the tenets of the Declaration of Helsinki. 
All participants gave written informed consent after being provided a thorough explanation of the procedures involved. The study's purpose and procedures were explained during the selection process, and only participants who agreed to voluntary participation were enrolled.

\section{Research instruments}

The study made use of standardized research tools, namely the World Health Organization Quality of Life Scale Brief Version (WHOQOL-BREF) and Tilburg Frailty Indicator (TFI) questionnaires.

The WHOQOL-BREF questionnaire is a shortened version of the WHOQOL-100 questionnaire, a general tool for assessing QoL. The WHOQOL-BREF questionnaire contains 26 questions. The first two relate to a selfassessment of each patient's QoL and state of health. The remaining questions comprise an assessment of QoL in four domains: physical, social, psychological, and environmental. Answers are given on a 5-point Likert scale. A maximum of 20 points can be scored in each domain, with a higher score indicating a higher QoL. ${ }^{22}$

The TFI questionnaire is made up of two parts. Part A characterizes each patient's sociodemographic profile, while part B comprises 15 questions that assess frailty in three domains. The physical domain (PD) ( $0-8$ points) includes physical health, unintentional weight loss, walking difficulties, impaired balance, impaired hearing and sight, impaired hand strength, and physical fatigue. The psychological domain (PsD) (0-4 points) includes symptoms of fear or depression, memory issues, and coping with problems. The social domain (SD) (0-3 points) includes social relations, social support, and solitary living. The overall score for the TFI questionnaire is in the range of $0-15$ points. A score of $\geq 5$ indicates FS. The higher the score, the higher the level of $\mathrm{FS}^{23-25}$

\section{Data analysis}

Quantitative analysis was performed by calculating the mean (M), standard deviation (SD), median, quartiles, minimum, and maximum. After this, the number and percentage occurrences of each value were found. Statistical comparisons were performed using the Mann-Whitney U test or the Kruskal-Wallis test (due to a non-normal distribution). When these tests determined a significant difference, a post hoc analysis was conducted using the Dunn test. Correlations between two variables were analysed using the Spearman correlation test (eg, rs - Spearman Rank-order Coefficient).
The strength of the correlations were measured according to the following scheme: $|r| \geq 0.9$ - very strong correlation, $0.7 \leq|\mathrm{r}|<0.9$ - strong correlation, $0.5 \leq|\mathrm{r}|<0.7$ - medium correlation, $0.3 \leq|r|<0.5$ - weak correlation and $|r|<0.3$ - very weak correlation (negligible) ${ }^{26}$ Multivariate analysis was performed using the linear regression method. The quality of the resulting model was assessed by calculating the $R^{2}$ determination coefficient. The normality distribution of any given variable was assessed using the Shapiro-Wilk test.

In all calculations, a significance threshold of 0.05 was used. Statistical analyses were performed using version 3.2.3 of the R statistical package.

\section{Results}

\section{Characteristics of the study group}

One hundred patients (61 men and 39 women, with a mean age of $\mathrm{M} \pm \mathrm{SD}=66.12 \pm 10.92$ years) took part in the study. They had all experienced NSTEMI and undergone percutaneous coronary intervention (PCI). In the study group, the largest proportion was made up of married individuals $(63 \%)$ and most lived in a city (73\%). Concerning education, $47 \%$ of the patients had a secondary education, $32 \%$ had primary education, and $21 \%$ had a higher education. Within the group, $34 \%$ were professionally active. Tobacco smoking was declared by $24 \%$ of those studied. The most frequent comorbidities were hypertension (70\%), hyperlipidaemia (32\%), and diabetes (30\%). The mean duration of CAD was 8.48 years and the mean number of hospitalizations due to cardiovascular diseases (CVD) in the last year was 1.82 . The socioclinical characteristics are summarized in Table 1.

In the study group, $80 \%$ had FS. In the TFI questionnaire, the psychological domain was the most significant, which exhibited the following results: $\mathrm{M} \pm \mathrm{SD}=2.2 \pm 0.75$ points out of 4 , or $55 \%$ of the maximum score. The physical domain was only slightly less important, at $\mathrm{M} \pm \mathrm{SD}=4.32 \pm 1.92$ points out of 8 , or $54 \%$ of the maximum score. The least meaningful was the social domain, which gave the following results: $\mathrm{M} \pm \mathrm{SD}=1.02 \pm 0.77$ points out of 3 , or $34 \%$ of the maximum score.

The self-assessed QoL was $\mathrm{M} \pm \mathrm{SD}=3.68 \pm 0.71$ points, indicating a result between a good and average QoL. The self-assessed health status was $\mathrm{M} \pm \mathrm{SD}=2.59 \pm 0.98$ points, indicating a result between an unsatisfactory and average health status.

The study group assigned the highest QoL ratings within the psychological domain, closely followed by the 
Table I Socioclinical characteristics of the study group. Results of the TFI and WHOQOL-BREF questionnaires

\begin{tabular}{|c|c|c|c|}
\hline \multicolumn{2}{|l|}{ Characteristics } & \multirow{2}{*}{$\frac{\mathbf{N}}{61 / 39}$} & \multirow{2}{*}{$\frac{\%}{61 \% / 39 \%}$} \\
\hline Gender & Male/female & & \\
\hline \multirow[t]{4}{*}{ Marital Status } & Married/living with partner & 63 & $63 \%$ \\
\hline & Unmarried & 10 & $10 \%$ \\
\hline & Separated/divorced & 6 & $6 \%$ \\
\hline & Widow/widower & 21 & $21 \%$ \\
\hline \multirow[t]{3}{*}{ Education } & None or primary & 32 & $32 \%$ \\
\hline & Secondary & 47 & $47 \%$ \\
\hline & Vocational or higher & 21 & $21 \%$ \\
\hline \multirow[t]{3}{*}{ Professional status } & Working & 34 & $34 \%$ \\
\hline & Retired & 59 & $59 \%$ \\
\hline & Pensioner/on benefits & 7 & $7 \%$ \\
\hline Place of residence & City/countryside & $76 / 24$ & $76 \% / 24 \%$ \\
\hline \multirow[t]{5}{*}{ Comorbidities* } & Diabetes & 30 & $30 \%$ \\
\hline & Hypertension & 70 & $70 \%$ \\
\hline & Hyperlipidemia & 32 & $32 \%$ \\
\hline & Other & 57 & $57 \%$ \\
\hline & None & 13 & $13 \%$ \\
\hline \multirow[t]{5}{*}{ Medication* } & Platelet inhibitors & 89 & $89 \%$ \\
\hline & ACE-I/ARB & 84 & $84 \%$ \\
\hline & Beta-blockers & 85 & $85 \%$ \\
\hline & Statins & 87 & $87 \%$ \\
\hline & None of the above & 10 & $10 \%$ \\
\hline Smoking & Nonsmoker/smoker & $76 / 24$ & $76 \% 24 \%$ \\
\hline \multirow[t]{2}{*}{ TFI } & Nonfrail/frail & $20 / 80$ & $20 \% / 80 \%$ \\
\hline & & Mean (SD) & Median $\left(Q_{1}-Q_{3}\right)$ \\
\hline \multirow{3}{*}{\multicolumn{2}{|c|}{$\begin{array}{l}\text { Age [years] } \\
\text { Number of hospitalizations due to CVD in the last year } \\
\text { Duration of CAD [years] }\end{array}$}} & $66.12(10.92)$ & $67(6 \mathrm{I} .75-73)$ \\
\hline & & $1.82(1.12)$ & $2(I-2)$ \\
\hline & & $8.48(7.47)$ & $6(2-14)$ \\
\hline \multirow[t]{3}{*}{ TFI } & Physical components & $4.32(1.97)$ & $5(306)$ \\
\hline & Psychological components & $2.2(0.75)$ & $2(2-3)$ \\
\hline & Social components & $1.02(0.77)$ & $I(I-I)$ \\
\hline \multirow[t]{6}{*}{ WHOQOL BREF } & Perceived QOL & $3.68(0.7 I)$ & $4(3-4)$ \\
\hline & Perceived quality of health & $2.59(0.98)$ & $3(2-3)$ \\
\hline & Physical domain & $12.03(2.72)$ & $12(10-14)$ \\
\hline & Psychological domain & 15.47 (1.98) & $16(14-17)$ \\
\hline & Social domain & $14.69(2.25)$ & $15(13-16)$ \\
\hline & Environmental domain & $15.3(1.91)$ & $16(14-16)$ \\
\hline
\end{tabular}

Note: *The percentages do not add up to 100 because this was a multiple choice question.

Abbreviations: TFI, Tilburg Frailty Indicator; WHOQOL BREF, World Health Organization QOL BREF questionnaire; $\mathrm{n}$, sample size; SD, standard deviation; CVD, cardiovascular disease; CAD, coronary artery disease; QI, quartile Ist; Q3, quartile 3rd; ACE-I, angiotensin-converting enzyme inhibitor; ARB, angiotensin receptor blocker; QoL, quality of life.

environmental domain. The worst ratings were in the social and physical domains. The data from the WHOQOL-BREF and TFI questionnaires are summarized in Table 1.

\section{The effect of FS on QOL following ACS}

The WHOQOL-BREF results were not normally distributed in the analyzed groups (Shapiro-Wilk test, $p<0.05$ ), so the analysis was conducted using the Mann-Whitney test. In univariate analysis all $p$-values were below 0.05 ; therefore, in all the domains, QoL depended on the occurrence of FS, meaning that patients with FS were found to have lower QoL.

The physical domain of TFI significantly affected all domains of QoL $(p<0.05)$. These relationships were negative: the more points in PD were, the lower the QoL in 
each domain. The strongest effect on the physical domain came from the PD of TFI ( $\mathrm{rs}=-0.619)$.

The SD of TFI significantly affected QoL in the psychological and social domains $(p<0.05)$. These relationships were negative: the more points in PD were, the lower the QoL was in each domain. The PsD of TFI did not significantly affect any of the QoL domains ( $p>0.05)$.

The multivariate analysis showed that the PD of TFI significantly affected QoL in all domains $(p<0.05)$, except the social domain. The SD of TFI had an impact on QoL in the social domain $(p<0.011$; Tables $2-7)$. These relationships were negative: the more points in PD were, the lower the QoL in each domain.

\section{The effects of age and gender on QOL in patients following ACS}

The univariate analysis found a statistically significant $(p<0.05)$ negative correlation between patient age and perceived QoL, perceived health, and the physical, psychological, social, and environmental domains of QoL. This means that the older the patient is, the worse will be their assessed QoL. In the multivariate analysis, it was noticed that age had a negative impact on QoL only in the social domain $(p=0.024)$. In the univariate analysis gender influences all QoL domains. Furthermore, men recorded a higher QoL than women $\operatorname{did}(p<0.05$; Tables $2-7)$. In the multivariate analysis gender only influences the psychological domain of QoL. Women had a worse QoL than men $(p=0.007)$.

\section{The number of hospitalizations and duration of illness versus QOL}

The number of hospitalizations significantly affected the perceived QoL and health, as well as QoL in the physical and environmental domains $(p<0.05)$. These relationships were negative: more hospitalizations were associated with a lower QoL in the domains above. The duration of illness had a significant impact on the self-perception of health and QoL in the physical and environmental domains $(p<0.05)$. These relationships were negative: the longer the illness duration, the lower the QoL in the domains above. In the multivariate analysis, no significant variables with reference to the number of hospitalizations and the duration of illness were recorded.

Data regarding perceived QoL and health, as well as the effects of TFI and selected socioclinical factors on QoL, are summarized in Tables 2-7.

\section{Discussion}

The main finding of this study was the correlation between the co-occurrence of FS and patient QoL following ACS. Global populations are living increasingly longer, even when compared with a few decades ago. This has led to an increased number of comorbidities, increased dependency and disability, lower QoL, and higher healthcare costs. ${ }^{27}$ More importantly, the number of older patients with co-occurring FS is increasing.

Older patients do not necessarily respond to existing guidelines for the treatment of ACS. Previous studies of older patients with many comorbidities and FS have shown that following the recommended treatments for ACS is not always optimal, and may produce poor results. $^{28}$

Correlations of clinical and subclinical determinants of CVD and FS have been documented. ${ }^{29}$ This relationship explicitly shows that FS can lead to the development of CVD and that CVD, in turn, can lead to the further occurrence of FS. Nevertheless, there is an insufficient body of research relating to the relationship between FS and ACS. It is believed that FS occurs three times more often in individuals with cardiovascular diseases than in the general population, resulting in this group of patients having an increased frequency of rehospitalization and rate of morbitity. ${ }^{29,30}$ Our study has shown that the co-occurrence of FS, assessed using the TFI questionnaire, is common in older patients experiencing ACS, with an incidence rate of $80 \%$. Such a high number of patients with FS may result from the tool we used. Multidimensional tools in the FS assessment are characterized by a higher percentage of FS identification than one-dimensional tools. Nevertheless, we applied a multidimensional tool because we wanted to have a more extensive vison of all domains (physical, psychological and social) which was justified by a holistic approach to health according to the World Health Organization.

These patients are also characterized by an increased frequency of rehospitalization within a year due to CAD. Similar results were found in a study by Salinas et $\mathrm{al}^{31}$ where over $70 \%$ of patients had FS based on the SHAREFI (Survey of Health, Ageing and Retirement in Europe index). This group was dominated by women and patients with multiple comorbidities, a high risk on the GRACE (Global Registry of Acute Coronary Events) and TIMI (Thrombolysis In Myocardial Infarction) scales, and a high-risk score according to the CRUSADE (Can Rapid 
Table 2 The effect of TFI and socioclinical factors on perceived QoL

\begin{tabular}{|c|c|c|c|c|c|c|c|c|}
\hline \multicolumn{2}{|c|}{ Variable } & \multicolumn{4}{|l|}{ Multivariate analysis* } & \multicolumn{3}{|c|}{ Univariate analysis } \\
\hline & & & & & & \multicolumn{2}{|c|}{ Correlation coefficient } & \multirow[t]{2}{*}{$p^{* *}$} \\
\hline & & Regression parameter & \multicolumn{2}{|c|}{$95 \% \mathrm{Cl}$} & $\boldsymbol{p}$ & Mean (SD) & Median (quartiles) & \\
\hline \multicolumn{2}{|c|}{ Physical components } & -0.172 & -0.277 & -0.067 & 0.002 & \multicolumn{2}{|l|}{-0.452} & $<0.001$ \\
\hline \multicolumn{2}{|c|}{ Psychological components } & -0.089 & -0.262 & 0.085 & 0.313 & \multicolumn{2}{|l|}{-0.025} & 0.806 \\
\hline \multicolumn{2}{|c|}{ Social components } & $-0.07 \mid$ & -0.266 & 0.124 & 0.47 & \multicolumn{2}{|l|}{-0.17} & 0.091 \\
\hline \multicolumn{2}{|c|}{ Age } & -0.008 & -0.025 & 0.01 & $0.38 I$ & \multicolumn{2}{|l|}{-0.191} & 0.058 \\
\hline \multicolumn{2}{|c|}{$\begin{array}{l}\text { Number of hospitalisztions due } \\
\text { to CVD in the last year }\end{array}$} & -0.063 & -0.186 & 0.059 & 0.308 & \multicolumn{2}{|l|}{-0.227} & 0.023 \\
\hline \multicolumn{2}{|c|}{ Illness duration } & 0.002 & -0.017 & 0.021 & 0.831 & \multicolumn{2}{|l|}{-0.161} & 0.11 \\
\hline \multirow{4}{*}{$\begin{array}{l}\text { TFI } \\
\text { Gender }\end{array}$} & No frailty & Ref. item & & & & $4.1(0.55)$ & $4(4-4)$ & 0.003 \\
\hline & Frailty & 0.345 & -0.141 & 0.831 & 0.162 & $3.58(0.7 I)$ & $4(3-4)$ & \\
\hline & Male & Ref. item & & & & $3.82(0.72)$ & $4(3-4)$ & 0.008 \\
\hline & Female & -0.182 & -0.47 & 0.106 & 0.212 & $3.46(0.64)$ & $3(3-4)$ & \\
\hline
\end{tabular}

Notes: *Adjusted to marital status, education, professional status, place of residence, comorbidities, medication, smoking. **Mann-Whitney test/Kruskal-Wallis test. Abbreviations: TFI, Tilburg Frailty Indicator; SD, standard deviation; Cl, confidence interval; ref., referral; QoL, quality of life.

Table 3 The effect of TFI and socioclinical factors on perceptions of health

\begin{tabular}{|c|c|c|c|c|c|c|c|c|}
\hline \multirow{3}{*}{\multicolumn{2}{|c|}{ Variable }} & \multirow{2}{*}{\multicolumn{4}{|c|}{ Multivariate analysis* }} & \multicolumn{3}{|l|}{ Univariate analysis } \\
\hline & & & & & & \multicolumn{2}{|l|}{ Correlation coefficient } & \multirow[t]{2}{*}{$\mathbf{p}^{* *}$} \\
\hline & & Regression parameter & \multicolumn{2}{|c|}{$95 \% \mathrm{Cl}$} & $p$ & Regression parameter & $95 \% \mathrm{Cl}$ & \\
\hline \multicolumn{2}{|c|}{ Physical components } & -0.28 & -0.428 & -0.132 & $<0.001$ & \multicolumn{2}{|l|}{-0.545} & $<0.001$ \\
\hline \multicolumn{2}{|c|}{ Psychological components } & -0.023 & -0.267 & 0.222 & 0.853 & \multicolumn{2}{|l|}{0.014} & 0.888 \\
\hline \multicolumn{2}{|c|}{ Social components } & -0.047 & -0.322 & 0.227 & 0.732 & \multicolumn{2}{|l|}{-0.15} & 0.136 \\
\hline \multicolumn{2}{|c|}{ Age } & 0.011 & -0.013 & 0.036 & 0.369 & \multicolumn{2}{|l|}{-0.138} & 0.172 \\
\hline \multicolumn{2}{|c|}{$\begin{array}{l}\text { Number of hospitalizations in } \\
\text { the last year }\end{array}$} & -0.042 & -0.215 & 0.131 & 0.631 & \multicolumn{2}{|l|}{-0.207} & 0.038 \\
\hline \multicolumn{2}{|c|}{ Illness duration } & -0.015 & -0.042 & 0.013 & 0.288 & \multicolumn{2}{|l|}{-0.264} & 0.008 \\
\hline \multirow[t]{2}{*}{ TFI } & No frailty & Ref. item & & & & $3.25(0.79)$ & $3(3-4)$ & 0.001 \\
\hline & Frailty & 0.154 & -0.53 & 0.838 & 0.656 & $2.42(0.95)$ & $2(2-3)$ & \\
\hline \multirow[t]{2}{*}{ Gender } & Male & Ref. item & & & & $2.75(1.01)$ & $3(2-4)$ & 0.026 \\
\hline & Female & -0.25 & -0.655 & 0.155 & 0.224 & $2.33(0.87)$ & $2(2-3)$ & \\
\hline
\end{tabular}

Notes: *Adjusted to marital status, education, professional status, place of residence, comorbidities, medication, smoking. **Mann-Whitney test/Kruskal-Wallis test. Abbreviations: TFI, Tilburg Frailty Indicator; SD, standard deviation; $\mathrm{CI}$, confidence interval; ref., referral.

Risk Stratification of Unstable Angina Patients Suppress Adverse Outcomes with Early implementation of the ACC/AHA Guidelines) model.

Our results concerning the incidence of FS are almost twice as high as those found in the study by Ekerstad et $\mathrm{al}^{32}$ where FS afflicted less than half of those studied. However, the other study did recognize FS as a strong independent predictor of hospitalization for 30 days or more and of in-hospital mortality. Moreover, a group of those patients had a higher risk of repeated MI, secondary coronary angioplasty, the occurrence of side effects such as heavy bleeding or stroke, and death. In the study by Kang et $\mathrm{al}^{33}$ where $40 \%$ out of a total of 352 patients were found to have FS, it was confirmed that in individuals with $\mathrm{ACS}, \mathrm{FS}$ is a strong and independent predictor of shortterm treatment results.

The importance of FS in the determination of patient biopsychosocial states must be emphasized. Although 
Table 4 Effects of TFI and socioclinical factors on the physical area of QoL

\begin{tabular}{|c|c|c|c|c|c|c|c|c|}
\hline \multicolumn{2}{|c|}{ Variable } & \multirow{2}{*}{\multicolumn{4}{|c|}{ Multivariate analysis* }} & \multicolumn{3}{|l|}{ Univariate analysis } \\
\hline & & & & & & \multicolumn{2}{|l|}{ Correlation coefficient } & \multirow{2}{*}{$p^{* *}$} \\
\hline & & Regression parameter & \multicolumn{2}{|c|}{$95 \% \mathrm{Cl}$} & $p$ & Regression parameter & $95 \% \mathrm{Cl}$ & \\
\hline \multicolumn{2}{|c|}{ Physical components } & -0.657 & -1.032 & -0.282 & 0.001 & \multicolumn{2}{|l|}{-0.619} & $<0.001$ \\
\hline \multicolumn{2}{|c|}{ Psychological components } & -0.365 & -0.987 & 0.256 & 0.245 & \multicolumn{2}{|l|}{-0.137} & 0.173 \\
\hline \multicolumn{2}{|c|}{ Social components } & 0.426 & $-0.27 \mid$ & 1.123 & 0.227 & \multicolumn{2}{|l|}{-0.118} & 0.243 \\
\hline \multicolumn{2}{|l|}{ Age } & 0.006 & -0.056 & 0.069 & 0.837 & \multicolumn{2}{|l|}{-0.34} & 0.001 \\
\hline \multicolumn{2}{|c|}{$\begin{array}{l}\text { Number of hospitalizations } \\
\text { in the last year }\end{array}$} & -0.393 & -0.832 & 0.046 & 0.079 & \multicolumn{2}{|l|}{-0.336} & 0.001 \\
\hline \multicolumn{2}{|c|}{ Illness duration } & -0.037 & -0.106 & 0.032 & 0.293 & \multicolumn{2}{|l|}{-0.376} & $<0.001$ \\
\hline \multirow{4}{*}{$\begin{array}{l}\text { TFI } \\
\text { Gender }\end{array}$} & No frailty & Ref. item & & & & $14.7(2.2)$ & $14.5(13-17)$ & $<0.001$ \\
\hline & Frailty & -0.242 & -1.98 & 1.496 & 0.783 & $11.36(2.42)$ & $11(10-13)$ & \\
\hline & Male & Ref. item & & & & $\mid 2.44(2.9 \mid)$ & $13(\mid 1-14)$ & 0.058 \\
\hline & Female & -0.468 & -1.498 & $0.56 \mathrm{I}$ & 0.368 & II.38 (2.3) & $11(10-13)$ & \\
\hline
\end{tabular}

Notes: *Adjusted to marital status, education, professional status, place of residence, comorbidities, medication, smoking.

**Mann-Whitney test/Kruskal-Wallis test.

Abbreviations: TFI, Tilburg Frailty Indicator; SD, standard deviation; Cl, confidence interval; ref., referral; QoL, quality of life.

Table 5 Effects of TFI and socioclinical factors on the psychological area of QoL

\begin{tabular}{|c|c|c|c|c|c|c|c|c|}
\hline \multirow{3}{*}{\multicolumn{2}{|c|}{ Variable }} & \multirow{2}{*}{\multicolumn{4}{|c|}{ Multivariate analysis* }} & \multicolumn{3}{|l|}{ Univariate analysis } \\
\hline & & & & & & Correlation coefficient & & $\mathbf{p}^{* *}$ \\
\hline & & Regression parameter & \multicolumn{2}{|c|}{$95 \% \mathrm{Cl}$} & $p$ & Regression parameter & $95 \% \mathrm{Cl}$ & \\
\hline \multicolumn{2}{|c|}{ Physical components } & -0.579 & -0.883 & -0.276 & $<0.001$ & \multicolumn{2}{|l|}{-0.475} & $<0.001$ \\
\hline \multicolumn{2}{|c|}{ Psychological components } & -0.06 & -0.563 & 0.443 & 0.813 & \multicolumn{2}{|l|}{0.022} & 0.831 \\
\hline \multicolumn{2}{|c|}{ Social components } & -0.465 & -1.03 & 0.099 & 0.105 & \multicolumn{2}{|l|}{-0.238} & 0.017 \\
\hline \multicolumn{2}{|c|}{ Age } & -0.042 & -0.093 & 0.009 & 0.102 & \multicolumn{2}{|l|}{-0.21} & 0.036 \\
\hline \multicolumn{2}{|c|}{$\begin{array}{l}\text { Number of hospitalizations } \\
\text { in the last year }\end{array}$} & -0.129 & -0.485 & 0.227 & 0.472 & \multicolumn{2}{|l|}{-0.167} & 0.098 \\
\hline \multicolumn{2}{|c|}{ Illness duration } & 0.005 & -0.051 & 0.061 & 0.853 & \multicolumn{2}{|l|}{-0.185} & 0.065 \\
\hline \multirow[t]{2}{*}{ TFI } & No frailty & Ref. item & & & & $16.65(1.53)$ & $17(16-17)$ & 0.004 \\
\hline & Frailty & 1.075 & -0.333 & 2.483 & 0.133 & $15.18(1.98)$ & $15(13-17)$ & \\
\hline \multirow[t]{2}{*}{ Gender } & Male & Ref. item & & & & $16.03(1.78)$ & $16(15-17)$ & $<0.001$ \\
\hline & Female & -1.157 & -1.991 & -0.323 & 0.007 & I4.59 (I.98) & $15(13-16)$ & \\
\hline
\end{tabular}

Notes: *Adjusted to marital status, education, professional status, place of residence, comorbidities, medication, smoking.

**Mann-Whitney test/Kruskal-Wallis test.

Abbreviations: TFI, Tilburg Frailty Indicator; SD, standard deviation; $\mathrm{Cl}$, confidence interval; ref., referral; QoL, quality of life.

there is an insufficient number of studies that relate to FS and QoL, FS undoubtedly has a negative effect on the QoL of patients with CAD. ${ }^{34}$ One study in particular, which used the MacNewHD-HRQL (MacNew Heart Disease Health-related QoL) questionnaire, showed a negative correlation between FS and QoL in patients with ACS. ${ }^{35}$

In the univariate analysis, in patients with co-occurring FS it was found to have a significant and negative effect on all aspects of QoL. A further analysis of the TFI questionnaire in three subscales found that the most significant domains of FS in the study group are psychological and physical. These results are in accord with those of Coelho et $\mathrm{al}^{36}$ who also studied the multidimensional context of FS. Despite an equally important psychological role in FS, the physical domain turned out to be the determining factor affecting disability and low QoL. The need for a multidimensional analysis of FS is also confirmed by research from Uchmanowicz et $\mathrm{al}^{37}$ that 
Table 6 Effects of TFI and socioclinical factors on the social area of QoL

\begin{tabular}{|c|c|c|c|c|c|c|c|c|}
\hline \multirow{3}{*}{\multicolumn{2}{|c|}{ Variable }} & \multirow{2}{*}{\multicolumn{4}{|c|}{ Multivariate analysis* }} & \multicolumn{3}{|l|}{ Univariate analysis } \\
\hline & & & & & & \multicolumn{2}{|l|}{ Correlation coefficient } & \multirow{2}{*}{$\mathbf{p}^{* *}$} \\
\hline & & Regression parameter & \multicolumn{2}{|c|}{$95 \% \mathrm{Cl}$} & $p$ & Regression parameter & $95 \% \mathrm{Cl}$ & \\
\hline \multicolumn{2}{|c|}{ Physical components } & -0.298 & -0.646 & 0.049 & 0.092 & \multicolumn{2}{|l|}{-0.279} & 0.005 \\
\hline \multicolumn{2}{|c|}{ Psychological components } & -0.101 & -0.677 & 0.474 & 0.727 & \multicolumn{2}{|l|}{0.016} & 0.878 \\
\hline \multicolumn{2}{|c|}{ Social components } & -0.67 & -1.316 & -0.025 & 0.042 & \multicolumn{2}{|l|}{-0.253} & 0.011 \\
\hline \multicolumn{2}{|l|}{ Age } & -0.067 & -0.125 & -0.009 & 0.024 & \multicolumn{2}{|l|}{-0.269} & 0.007 \\
\hline \multirow{2}{*}{\multicolumn{2}{|c|}{$\begin{array}{l}\text { Number of hospitalizations } \\
\text { in the last year } \\
\text { Illness duration }\end{array}$}} & 0.127 & -0.28 & 0.533 & 0.538 & \multicolumn{2}{|l|}{-0.122} & 0.225 \\
\hline & & 0.005 & -0.06 & 0.069 & 0.883 & -0.173 & & 0.086 \\
\hline \multirow[t]{2}{*}{$\mathrm{TFI}$} & No frailty & Ref. item & & & & $16.05(2.31)$ & $15.5(15-17)$ & 0.013 \\
\hline & Frailty & 0.191 & -1.419 & 1.802 & 0.814 & $14.35(2.12)$ & $15(13-16)$ & \\
\hline \multirow[t]{2}{*}{ Gender } & Male & Ref. item & & & & $15.16(2.21)$ & $15(13-16)$ & 0.017 \\
\hline & Female & -0.302 & -1.257 & 0.652 & 0.53 & I3.95 (2.14) & $15(13-15.5)$ & \\
\hline
\end{tabular}

Notes: *Adjusted to marital status, education, professional status, place of residence, comorbidities, medication, smoking. **Mann-Whitney test/Kruskal-Wallis test. Abbreviations: TFI, Tilburg Frailty Indicator; SD, standard deviation; Cl, confidence interval; ref., referral; QoL, quality of life.

Table 7 The effects of TFI and socioclinical factors on the environmental area of QoL

\begin{tabular}{|c|c|c|c|c|c|c|c|c|}
\hline \multirow{3}{*}{\multicolumn{2}{|c|}{ Variable }} & \multirow{2}{*}{\multicolumn{4}{|c|}{ Multivariate analysis * }} & \multicolumn{3}{|l|}{ Univariate analysis } \\
\hline & & & & & & Correlation coefficient & & $p^{* *}$ \\
\hline & & Regression parameter & \multicolumn{2}{|c|}{$95 \% \mathrm{Cl}$} & $p$ & Regression parameter & $95 \% \mathrm{Cl}$ & \\
\hline \multicolumn{2}{|c|}{ Physical components } & -0.464 & -0.743 & -0.185 & 0.001 & \multicolumn{2}{|l|}{-0.467} & $<0.001$ \\
\hline \multicolumn{2}{|c|}{$\begin{array}{l}\text { Psychological } \\
\text { components }\end{array}$} & -0.183 & -0.645 & 0.279 & 0.434 & \multicolumn{2}{|l|}{-0.014} & 0.889 \\
\hline \multicolumn{2}{|c|}{ Social components } & -0.214 & -0.732 & 0.304 & 0.413 & \multicolumn{2}{|l|}{-0.165} & 0.101 \\
\hline \multicolumn{2}{|l|}{ Age } & -0.017 & -0.063 & 0.029 & 0.47 & \multicolumn{2}{|l|}{-0.27} & 0.007 \\
\hline \multicolumn{2}{|c|}{$\begin{array}{l}\text { Number of hospitaliza- } \\
\text { tions in the last year }\end{array}$} & -0.29 & -0.616 & 0.036 & 0.081 & \multicolumn{2}{|l|}{-0.309} & 0.002 \\
\hline \multicolumn{2}{|c|}{ Illness duration } & -0.009 & -0.06 & 0.043 & 0.744 & \multicolumn{2}{|l|}{-0.206} & 0.04 \\
\hline \multirow[t]{2}{*}{ TFI } & No frailty & Ref. item & & & & $16.4(1.98)$ & $16.5(15.75-18)$ & 0.004 \\
\hline & Frailty & 1.119 & -0.173 & 2.412 & 0.089 & $15.03(1.8)$ & $15(14-16)$ & \\
\hline \multirow[t]{2}{*}{ Gender } & Male & Ref. item & & & & $15.7(1.74)$ & $16(14-17)$ & 0.007 \\
\hline & Female & -0.32 & -1.086 & 0.446 & 0.408 & $14.67(2)$ & $14(14-16)$ & \\
\hline
\end{tabular}

Notes: *Adjusted to marital status, education, professional status, place of residence, comorbidities, medication, smoking. **Mann-Whitney test/Kruskal-Wallis test. Abbreviations: TFI, Tilburg Frailty Indicator; SD, standard deviation; Cl, confidence interval; ref., referral; QoL, quality of life.

considered the relationship between FS and the possibility of self-care in patients with chronic CAD. With feedback from the TFI questionnaire given to their study group, the authors demonstrated that a better level of self-care comes from the social domain. Research by Amer et $\mathrm{al}^{38}$ conducted on a group of 115 patients of an ambulatory geriatric clinic at Mansour Hospital in Egypt, also considered FS and QoL. The data analysis showed a strong, negative correlation between FS (as assessed by an EFS survey) and all dimensions of QoL in the RAND-36 health survey questionnaire. It was also observed that possible correlating factors of FS in assessing QoL are as follows: age, low socioeconomic status, low body mass index (BMI), functional dependence, impaired cognitive function, and depression. The effect of FS on lower QoL among patients with congestive heart failure was found by Uchmanowicz 
and Gobbens. ${ }^{39}$ They emphasized that FS was found in almost $90 \%$ of those studied and that as TFI scores increased, QoL decreased.

As indicated above, socioclinical variables have a significant impact on QoL scores. One of the important determinants that influences QoL turns out to be gender. The univariate analysis of the impact of gender on QoL clearly shows that males give a higher rating to QoL in all domains. Similar results were presented by Westin et al ${ }^{40}$ who compared QoL of men and women after acute MI and procedures such as coronary artery bypass grafting (CABG) or PCI. Among those surveyed, women declared a lower QoL, especially in terms of overall health and selfesteem. Agewall et $\mathrm{al}^{41}$ showed identical results both one and twelve months following ACS, indicating a lower QoL in women in all domains of the MacNew HDHRQoL questionnaire.

In many studies, age is considered one of the important predictors affecting general QoL, which may result from the deterioration of the biopsychosocial function of older patients. $^{42,43}$ Our univariate analysis clearly showed that the older the patient is, the lower their QoL will be in all domains. The negative influence of age as an independent determinant of lower QoL was also demonstrated in other studies of patients with ACS. ${ }^{44}$

What is more, the univariate analysis confirmed that a larger number of hospitalizations is associated with a lower QoL in the physical and environmental domains. Johansson et $\mathrm{al}^{45}$ showed that re-hospitalizations are associated with a lower QoL. The study of Iqbal et $\mathrm{al}^{46}$ showed that low QoL in patients with NSTEMI increases the risk of rehospitalization. In addition, the duration of the disease affects the perception of QoL. In the examined group of patients following ACS, a lower QoL was reported, especially in the physical and environmental domains. Hlatky et $\mathrm{al}^{47}$ demonstrated that the duration of the disease, mainly recurrent angina, was the main factor affecting QOL in all domains.

As stated above, a deficit in the number of studies on FS and QoL among patients with ACS persists. Support for increased research practices can be found in the observations of older patients by the authors of the few existing studies. Those previous studies that were not strictly tied to CVD also found that FS had a negative effect on QoL. ${ }^{48,49}$ The multidimensional aspect of FS confirms that, regardless of chronic illnesses or comorbidities, a lower QoL rating should be expected from all study groups of patients with FS. Conducting studies in the field of FS allows for early intervention. It aids in the identification of those individuals with
FS (or those at risk of developing it-so-called pre-frail patients) and in the ability to take actions individually adapted to each patient.

\section{Study limitations}

A limitation of this study could be its use of just one tool to identify FS. In clinical practice, there is a lack of guidelines for choosing a specific tool to assess FS in patients following ACS. Using a comparative tool would allow for the determination of the predictive capacity of various tests to assess FS in a similar patient group. In this study, there was no opportunity to identify FS initiallythat is, before the onset of ACS. Moreover, the study group only included patients with ACS of the NSTEMI type. Comparing STEMI and NSTEMI could provide valuable information about the differences in sociodemographic factors and incidence rates of FS co-occurrence between the two types of ACS.

\section{Practical implications}

This study proved that the identification of FS and the assessment of QoL among older patients with NSTEMI are important components of the diagnostic and therapeutic process; they should, therefore, be carried out routinely. Among cardiac patients with low QoL and the co-occurrence of FS, compensatory strategies should be sought to address biopsychosocial needs. One of the key criteria for establishing comprehensive care for older cardiac patients should be the definition of determinants, which can significantly affect the severity of FS symptoms and reduce QoL. The identification of these factors would allow for the early implementation of appropriate interventions to prevent the deepening of decompensation changes.

Every member of a therapeutic team, including nurses, plays an important role in FS management. From a clinical point of view, the assessment of FS is important in guaranteeing an optimal monitoring of patients with NSTEMI. Nurses should be oriented to implementing their own strategies for the care of older patients with FS. Interventions should be coordinated and their main purpose should be the early identification FS, the prevention of functional dependence, and the maintenance of a homeostatic balance. The prevention of FS may also reduce the number of hospitalizations due to CVD, as well as promote a higher QoL for patients with ACS. Achieving these goals is possible through the cooperation of multidisciplinary teams that are ready to conduct comprehensive assessments. 
In summary, desired treatment outcomes should be determined not only from factors like efficacy and increased survival but also from each patient having judged themselves to have a satisfactory QoL and overall state of well-being. The assessment of QoL among patients following ACS plays an important role in the therapeutic decision-making; therefore, it should be performed routinely. One of the goals of the comprehensive care of older cardiology patients with FS should be defining and countering the determinants that can significantly escalate FS symptoms and decrease QoL.

\section{Conclusions}

In conclusion, it was found that FS co-occurs in $80 \%$ of patients following ACS. It negatively affects all domains of QoL (physical, psychological, social, and environmental) among those patients. In this study, the psychological and physical domain of FS were found to be the most significant.

\section{Abbreviations list}

ACC, American College of Cardiology; ACS, acute coronary syndrome; AGS, the American Geriatrics Society; AHA, American Heart Association; BMI, body mass index; CAD, coronary artery disease; CHS, Cardiovascular Health Study scale; CI, cognitive impairment; CVD, cardiovascular diseases; DTBT, door-to-balloon time; ESC, the European Society of Cardiology; FS, frailty syndrome; GRACE, the Global Registry of Acute Coronary Events; IFFANIAM, The Impact of frailty and functional status in elderly patients with ST-segment elevation myocardial infarction undergoing primary angioplasty; MacNew HD-HRQL, the MacNew Heart Disease Health-related QoL; NSTEMI, non-ST elevation myocardial infarction; QoL, quality of life; PD, physical domain of TFI; PsD, psychosocial domain of TFI; SD, social domain of TFI; SHARE-FI, the Survey of Health, Ageing and Retirement in Europe index; STEMI, ST-segment-elevation myocardial infarction; STROBE, STrengthening the Reporting of OBservational studies in Epidemiology; TFI, Tilburg Frailty Indicator; TIMI, the Thrombolysis In Myocardial Infarction; WHOQOL-BREF, World Health Organization Quality of Life Scale Brief Version.

\section{Data sharing statement}

The authors confirm that all data underlying the findings described in this manuscript are fully available to all interested researchers upon request.

\section{Acknowledgments}

There were no contributors to the article other than the authors and there was no writing assistance regarding this paper. This study was conducted under a research project funded by the Ministry of Science and Higher Education in Poland as a part of a statutory grant of the Wroclaw Medical University for maintaining research potential (number ST.E020.17.050).

\section{Author contributions}

All authors contributed toward data analysis, drafting and critically revising the paper, gave final approval of the version to be published, and agree to be accountable for all aspects of the work.

\section{Disclosure}

The authors report no conflicts of interest in this work.

\section{References}

1. Go AS, Mozaffarian D, Roger VL, et al. Heart disease and stroke statistics-2013 update: a report from the American Heart Association. Circulation. 2013;127(1):e6-e245. doi:10.1161/ CIR.0b013e31828124ad

2. Hamm CW, Bassand J-P, Agewall S, et al. ESC Guidelines for the management of acute coronary syndromes in patients presenting without persistent ST-segment elevation: the task force for the management of acute coronary syndromes (ACS) in patients presenting without persistent ST-segment elevation of the European Society of Cardiology (ESC). Eur Heart J. 2011;32(23):2999-3054. doi:10.1093/eurheartj/ehr236

3. Ibanez B, James S, Agewall S, et al. 2017 ESC guidelines for the management of acute myocardial infarction in patients presenting with ST-segment elevation: the task force for the management of acute myocardial infarction in patients presenting with ST-segment elevation of the European Society of Cardiology (ESC). Eur Heart J. 2018;39 (2):119-177. doi:10.1093/eurheartj/ehx393

4. Goldberg RJ, Yarzebski J, Lessard D, Gore JM. A two-decades (1975 to 1995) long experience in the incidence, in-hospital and long-term case-fatality rates of acute myocardial infarction: a community-wide perspective. J Am Coll Cardiol. 1999;33(6):15331539.

5. Fox KAA, Dabbous OH, Goldberg RJ, et al. Prediction of risk of death and myocardial infarction in the six months after presentation with acute coronary syndrome: prospective multinational observational study (GRACE). BMJ. 2006;333(7578):1091. doi:10.1136/ bmj.38985.646481.55

6. Fach A, Bünger S, Zabrocki R, et al. Comparison of outcomes of patients with ST-segment elevation myocardial infarction treated by primary percutaneous coronary intervention analyzed by age groups $(<75,75$ to 85 , and $>85$ years); (Results from the Bremen STEMI registry). Am J Cardiol. 2015;116(12):1802-1809. doi:10.1016/j. amjcard.2015.09.022

7. Forman DE, Chen AY, Wiviott SD, Wang TY, Magid DJ, Alexander KP. Comparison of outcomes in patients aged $<75,75$ to 84 , and $\geq 85$ years with ST-elevation myocardial infarction (from the ACTION registry-GWTG). Am J Cardiol. 2010;106(10):1382-1388. doi:10.1016/j.amjcard.2010.07.008 
8. Yudi MB, Hamilton G, Farouque O, et al. Trends and impact of door-to-balloon time on clinical outcomes in patients aged $<75,75$ to 84 , and $\geq 85$ years with ST-elevation myocardial infarction. $\mathrm{Am}$ J Cardiol. 2017;120(8):1245-1253. doi:10.1016/j.amjcard.2017.07. 005

9. Yudi MB, Jones N, Fernando D, et al. Management of patients aged $\geq 85$ years with ST-elevation myocardial infarction. Am J Cardiol. 2016;118(1):44-48. doi:10.1016/j.amjcard.2016.04.010

10. Alexander KP, Newby LK, Armstrong PW, et al. Acute coronary care in the elderly, part II: ST-segment-elevation myocardial infarction: a scientific statement for healthcare professionals from the American Heart Association Council on Clinical Cardiology: in collaboration with the Society of Geriatric Cardiology. Circulation. 2007;115(19):2570-2589. doi:10.1161/ CIRCULATIONAHA.107.182616

11. Ariza-Solé A, Formiga F, Vidán MT, et al. Impact of frailty and functional status on outcomes in elderly patients with ST-segment elevation myocardial infarction undergoing primary angioplasty: rationale and design of the IFFANIAM study. Clin Cardiol. 2013;36(10):565-569. doi:10.1002/clc.22182

12. Sandhu KS, Singh A, Nadar SK. Management of elderly patients with troponin positive chest pain in a district general hospital. Cardiol J. 2012;19(4):395-401.

13. Caretta G, Passamonti E, Pedroni PN, Fadin BM, Galeazzi GL, Pirelli S. Outcomes and predictors of mortality among octogenarians and older with ST-segment elevation myocardial infarction treated with primary coronary angioplasty. Clin Cardiol. 2014;37(9):523529. doi:10.1002/clc.22313

14. Markle-Reid M, Browne G. Conceptualizations of frailty in relation to older adults. J Adv Nurs. 2003;44(1):58-68.

15. Slaets JPJ. Vulnerability in the elderly: frailty. Med Clin North Am. 2006;90(4):593-601. doi:10.1016/j.mcna.2006.05.008

16. Ferrucci L, Guralnik JM, Studenski S, et al. Designing randomized, controlled trials aimed at preventing or delaying functional decline and disability in frail, older persons: a consensus report. $\mathrm{J} \mathrm{Am}$ Geriatr Soc. 2004;52(4):625-634. doi:10.1111/j.15325415.2004.52174.x

17. Fried LP, Tangen CM, Walston J, et al. Frailty in older adults: evidence for a phenotype. J Gerontol A Biol Sci Med Sci. 2001;56 (3):M146-M156

18. Bandeen-Roche K, Xue Q-L, Ferrucci L, et al. Phenotype of frailty: characterization in the women's health and aging studies. J Gerontol A Biol Sci Med Sci. 2006;61(3):262-266.

19. Ensrud KE, Ewing SK, Cawthon PM, et al. A comparison of frailty indexes for the prediction of falls, disability, fractures, and mortality in older men. J Am Geriatr Soc. 2009;57(3):492-498. doi:10.1111/ j.1532-5415.2009.02137.x

20. Gill TM, Gahbauer EA, Allore HG, Han L. Transitions between frailty states among community-living older persons. Arch Intern Med. 2006;166(4):418-423. doi:10.1001/archinte.166.4.418

21. Graham JE, Snih SA, Berges IM, Ray LA, Markides KS, Ottenbacher KJ. Frailty and 10-year mortality in community-living Mexican American older adults. Gerontology. 2009;55(6):644-651. doi:10.1159/000235653

22. Wołowicka I, Jaracz K. Polish version of the WHOQOL - WHOQOL 100 and WHOQOL BREEF. In: Wołowicka I, Jaracz K, editors. Quality of Life in Medical Sciences. Poznan, Poland: Poznan Medical University Publisher; 2001:231-238.

23. Gobbens RJJ, van Assen MALM, Luijkx KG, Wijnen-Sponselee MT, Schols JMGA. The Tilburg frailty indicator: psychometric propertie s. $J$ Am Med Dir Assoc. 2010;11(5):344-355. doi:10.1016/j. jamda.2009.11.003

24. Uchmanowicz I, Jankowska-Polańska B, Uchmanowicz B, Kowalczuk K, Gobbens RJJ. Validity and reliability of the polish version of the Tilburg Frailty Indicator (TFI). J Frailty Aging. 2016;5 (1):27-32. doi:10.14283/jfa.2015.66
25. Uchmanowicz I, Jankowska-Polańska B, Łoboz-Rudnicka M, Manulik S, Łoboz-Grudzień K, Gobbens RJ. Cross-cultural adaptation and reliability testing of the Tilburg Frailty Indicator for optimizing care of Polish patients with frailty syndrome. Clin Interv Aging. 2014;9:997-1001. doi:10.2147/CIA.S64853

26. Hinkle DE, Wiersma W, Jurs SG. Applied Statistics for the Behavioral Sciences. 5 ed. Boston: Houghton Mifflin; 2002.

27. Marengoni A, Angleman S, Melis R, et al. Aging with multimorbidity: a systematic review of the literature. Ageing Res Rev. 2011;10 (4):430-439. doi:10.1016/j.arr.2011.03.003

28. Simms AD, Batin PD, Kurian J, Durham N, Gale CP. Acute coronary syndromes: an old age problem. J Geriatr Cardiol JGC. 2012;9 (2):192-196. doi:10.3724/SP.J.1263.2012.01312

29. Newman AB, Gottdiener JS, Mcburnie MA, et al. Associations of subclinical cardiovascular disease with frailty. J Gerontol A Biol Sci Med Sci. 2001;56(3):M158-M166.

30. Cacciatore F, Abete P, Mazzella F, et al. Frailty predicts longterm mortality in elderly subjects with chronic heart failure. Eur $J \quad$ Clin Invest. 2005;35(12):723-730. doi:10.1111/j.13652362.2005.01572.x

31. Alonso Salinas GL, Sanmartín Fernández M, Pascual Izco M, et al. Frailty is a short-term prognostic marker in acute coronary syndrome of elderly patients. Eur Heart J Acute Cardiovasc Care. 2016;5 (5):434-440. doi:10.1177/2048872616644909

32. Ekerstad N, Swahn E, Janzon M, et al. Frailty is independently associated with short-term outcomes for elderly patients with non-ST-segment elevation myocardial infarction. Circulation. 2011;124(22):2397-2404. doi:10.1161/CIRCULATIONAHA.1 11.025452

33. Kang L, Zhang S-Y, Zhu W-L, et al. Is frailty associated with shortterm outcomes for elderly patients with acute coronary syndrome? $J$ Geriatr Cardiol JGC. 2015;12(6):662-667. doi:10.11909/j.issn.16715411.2015.06.010

34. Singh M, Alexander K, Roger VL, et al. Frailty and its potential relevance to cardiovascular care. Mayo Clin Proc Mayo Clin. 2008;83(10):1146-1153. doi:10.4065/83.10.1146

35. Lisiak M, Uchmanowicz I, Wontor R. Frailty and quality of life in elderly patients with acute coronary syndrome. Clin Interv Aging. 2016;11:553-562. doi:10.2147/CIA.S99842

36. Coelho T, Paúl C, Gobbens RJJ, Fernandes L. Frailty as a predictor of short-term adverse outcomes. PeerJ. 2015;3:e1121. doi:10.7717/ peerj.1121

37. Uchmanowicz I, Wleklik M, Gobbens RJJ. Frailty syndrome and self-care ability in elderly patients with heart failure. Clin Interv Aging. 2015;10:871-877. doi:10.2147/CIA.S83414

38. Amer M, Akkad R, Hassan H. Correlation of frailty status to health related quality of life in the elderly: a cross-sectional study on community-dwelling older adults referred to an outpatient geriatric service in Egypt. Middle East J Age Ageing. 2015;12(1):3-12. doi:10.5742/MEAA.2015.92608.

39. Uchmanowicz I, Gobbens RJJ. The relationship between frailty, anxiety and depression, and health-related quality of life in elderly patients with heart failure. Clin Interv Aging. 2015;10:1595-1600. doi: 10.2147/CIA.S90077

40. Westin L, Carlsson R, Erhardt L, Cantor-Graae E. Differences in quality of life in men and women with ischemic heart disease: a prospective controlled study. Scand Cardiovasc J. 1999;33(3):160165. doi:10.1080/14017439950141795

41. Agewall S, Berglund M, Henareh L. Reduced quality of life after myocardial infarction in women compared with men. Clin Cardiol. 2004;27(5):271-274.

42. García EL, Banegas JR, Pérez-Regadera AG, Cabrera RH, Rodríguez-Artalejo F. Social network and health-related quality of life in older adults: a population-based study in Spain. Qual Life Res Int J Qual Life Asp Treat Care Rehabil. 2005;14(2):511520 . 
43. Zielińska-Więczkowska H, Kędziora-Kornatowska K, Ciemnoczołowski W. Evaluation of quality of life (QoL) of students of the University of Third Age (U3A) on the basis of socio-demographic factors and health status. Arch Gerontol Geriatr. 2011;53(2):e198-e202. doi:10.1016/j. archger.2010.09.003

44. Beck CA, Joseph L, Bélisle P, Pilote L. QOLAMI investigators (Quality of life in acute myocardial infarction). Predictors of quality of life 6 months and 1 year after acute myocardial infarction. Am Heart J. 2001;142(2):271-279. doi:10.1067/mhj.2001.116758

45. Johansson P, Dahlström U, Broström A. Factors and interventions influencing health-related quality of life in patients with heart failure: a review of the literature. Eur J Cardiovasc Nurs J Work Group Cardiovasc Nurs Eur Soc Cardiol. 2006;5(1):5-15. doi:10.1016/j.ejcnurse.2005.04.011

46. Iqbal J, Francis L, Reid J, Murray S, Denvir M. Quality of life in patients with chronic heart failure and their carers: a 3-year follow-up study assessing hospitalization and mortality. Eur J Heart Fail. 2010;12(9):1002-1008. doi:10.1093/eurjhf/hfq114
47. Hlatky MA, Boothroyd DB, Melsop KA, et al. Medical costs and quality of life 10 to 12 years after randomization to angioplasty or bypass surgery for multivessel coronary artery disease. Circulation. 2004 . Available from: https://www.ahajou rnals.org/doi/abs/10.1161/01.cir.0000143379.26342.5c. Accessed December 19, 2018.

48. Bilotta C, Bowling A, Casè A, et al. Dimensions and correlates of quality of life according to frailty status: a cross-sectional study on community-dwelling older adults referred to an outpatient geriatric service in Italy. Health Qual Life Outcomes. 2010;8:56. doi:10.1186/ 1477-7525-8-56

49. Eklund K, Wilhelmson K. Outcomes of coordinated and integrated interventions targeting frail elderly people: a systematic review of randomised controlled trials. Health Soc Care Community. 2009; 17 (5):447-458. doi:10.1111/j.1365-2524.2009.00844.x
Clinical Interventions in Aging

\section{Publish your work in this journal}

Clinical Interventions in Aging is an international, peer-reviewed journal focusing on evidence-based reports on the value or lack thereof of treatments intended to prevent or delay the onset of maladaptive correlates of aging in human beings. This journal is indexed on PubMed Central, MedLine, CAS, Scopus and the Elsevier

\section{Dovepress}

Bibliographic databases. The manuscript management system is completely online and includes a very quick and fair peer-review system, which is all easy to use. Visit http://www.dovepress.com/ testimonials.php to read real quotes from published authors. 